\title{
A EVOLUÇÃO DO PROCEDIMENTO DO REQUERIMENTO INICIAL NO ÂMBITO DO DEPARTAMENTO NACIONAL DE PRODUÇÃO MINERAL
}

\author{
Y. C. S. SANTOS ${ }^{1}$ \\ Departamento Nacional da Produção Mineral - DNPM \\ yolacir@yahoo.com.br ${ }^{1}$ \\ Artigo submetido em 13/12/2017 e aceito em 09/08/2019 \\ DOI: $10.15628 /$ holos.2019.6670
}

\section{RESUMO}

O presente estudo tem como objetivo a descrição cronológica da evolução da legislação e dos procedimentos no tocante ao requerimento inicial no âmbito da autarquia Departamento Nacional de Produção Mineral (DNPM). A partir da leitura dos Códigos de Minas de 1934 e de 1940 e do atual Código de Mineração de 1967, foi possível a verificação da evolução das técnicas cartográficas e geodésicas ao longo do tempo no sentido do estabelecimento do real posicionamento da área requerida, em face de áreas anteriormente requeridas. Ademais, retratou-se a evolução no âmbito do DNPM quanto à gestão destas informações, anteriormente repassados aos interessados por meio de representação e cartas e overlays e atualmente pelo moderno Sistema Informação Geográficas da Mineração (SIGMINE).

Palavras-chave: Legislação minerária, requerimentos, DNPM, Brasil.

\section{THE EVOLUTION OF THE INITIAL REQUEST PROCEDURE IN THE NATIONAL MINERAL PRODUCTION DEPARTMENT}

\begin{abstract}
The present study described in a chronological way the evolution of the legislation and the procedures regarding the initial application within the scope of the National Department of Mineral Production (DNPM). From a reading of the Mining Codes of 1934 and 1940 and the current Mining Code of 1967, it was possible to verify the evolution of cartographic and geodetic techniques over
\end{abstract}

time in order to establish the real position of the required area, in existing areas In addition, the evolution of the DNPM regarding the management of this information, previously passed on to stakeholders through representation and letters and overlays and currently by the modern Geographic Information System of Mining (SIGMINE), was portrayed.

KEYWORDS: Mining legislation, requirements, DNPM, Brazil 


\section{INTRODUÇÃO}

Nos termos do inciso IX do art. 20 da Carta Magna Brasileira, os recursos minerais, inclusive do subsolo, são bens da União. Por conseguinte, em face da União, não poder realizar a atividade de mineração propriamente dita, ela repassa à concessão a terceiros, garantindo a este a propriedade do produto da lavra (Constituição da República Federativa do Brasil, 1988). Todo o rito processual visando a autorização do Governo Federal para aproveitamento dos recursos minerais é ditado atualmente pelo Decreto Lei no 227/1967, conhecido como Código de Mineração, cabendo a autarquia Departamento Nacional de Produção Mineral (DNPM), vinculada ao Ministério de Minas e Energia (MME), a responsabilidade pela gestão do patrimônio mineral brasileiro.

Nestes termos, a parte principal do rito processual, refere-se ao requerimento inicial que dentre outras coisas, definirá a real localização da área de interesse, bem como a representação desta no banco de dados do DNPM. Cabe destacar, que prevalece na legislação minerária, o direito a prioridade, que garante no caso de dois requerimentos definidos pelo mesmo memorial descritivo, o direito à área, a quem primeiro realizou o requerimento junto ao DNPM.

Dentro desta temática, o presente artigo tem como objetivo principal o relato, à luz das legislações minerárias vigentes em cada época, da evolução do procedimento do requerimento inicial ao DNPM, levando em consideração os aspectos técnicos vinculados à demarcação e representação das áreas de interesse. Insta informar, que a base teórica escolhida para o presente trabalho, constituiu-se do arcabouço jurídico das legislações minerárias, bem como os manuais técnicos disponibilizados pelo DNPM ao longo do tempo.

\section{O REQUERIMENTO INICIAL NO DNPM ATRAVÉS DOS TEMPOS}

Nogueira (2004) descreve que os tratamentos dispensados à dominialidade dos recursos minerais foram caracterizados sobremaneira pelo regime político dominante em cada época da história. Em síntese, persistiu no Brasil quatro sistemas distintos de propriedade mineral: sistema regaliano, sistema dominial imperial, sistema fundiário ou da acessão, e finalmente, o sistema de autorização e concessão. No sistema regaliano, vigente durante o período colonial, as jazidas minerais eram de propriedade da Coroa Portuguesa, cabendo ao responsável pelas atividades de lavra, o pagamento à Coroa do quinto ou dízimo (PAIVA, 1967). O regime dominial imperial, iniciado a partir da Independência do Brasil, difere do primeiro, no aspecto da dominialidade, antes da Coroa, naquela oportunidade, pertencente ao Império (TAVORA, 1955). Com o advento da República, passou a vigorar o sistema fundiário ou da acessão, que consiste na tese que o proprietário da coisa principal é também, o da coisa acessória, ou seja, a propriedade da jazida pertencia ao dono do solo, comumente denominado superficiário. Por fim, a partir da promulgação da Constituição Federal de 1934, surge, o sistema de autorização e concessão, baseado na dualidade do domínio, pelo qual as jazidas pertencem ao Poder Público, cabendo a este, conceder a um interessado o direito da exploração, por ato administrativo próprio (NOGUEIRA, 2004). 
Nesta esteira, e na égide do sistema de autorização e concessão, houve em 08/03/1934, através do Decreto no 23.979, a criação do DNPM, e em 10/07/1934, através do Decreto no 24.642, o Código de Minas de 1934. Este último, garantiu aos então detentores de minas ou jazidas, a propriedade destas, desde que houvesse a manifestação formal nos termos da legislação ora vigente. O requerimento, no âmbito do Código de 1934, e obedecidos os termos do inciso IV do art. 10, exigia do interessado, dentre outros, a apresentação de:

c)-provas da existência da jazida, a saber: um caixote com amostras do minerio (em garrafas, si se tratar de substancias liquidas ou gazosas), planta da jazida (embora tosca, mas de preferencia em escala metrica), e, sendo possivel, relatorios, pareceres, photographias e mais esclarecimentos sôbre a existencia da jazida;

d)-modo de occorrencia da jazida, isto é, descrição (quanto mais minuciosa, melhor) da jazida e seus arredores, e a área, embora approximada, em metros quadrados, occupada pela jazida ou seus affloramentos, onde quer que o minerio seja notado á simples vista ou por escavações superficiaes;

e)-situação topographica da jazida, isto é, distancia e obstaculos de communicação a vencer entre a jazida e o caminho mais proximo, natureza desse caminho e sua distancia até encontrar o ponto mais accessivel servido por estrada de ferro ou de rodagem ou por porto de embarque em rio ou mar, e sendo possivel, uma planta (embora tosca, de preferencia em escala metrica) que represente o que acaba de ser dito (BRASIL, 1934) .

Em 1940, houve a promulgação do Decreto-Lei no 1.985, denominado de Código de Minas de 1940, em substituição ao Código de Minas de 1934, que solicitava do interessado, para fins de requerimento, a apresentação, dentre outros, do seguinte elemento de instrução:

Declaração dos nomes dos proprietários dos imóveis atingidos e definição da área requerida quer por limites naturais e confrontações, com o esbôço topográfico, quer por figuras geométricas traçadas em relação a pontos inequivocamente definidos, quer por plantas autênticas, amarradas a pontos fixos no terreno (BRASIL, 1940)

O requerimento inicial era direcionado ao Ministro da Agricultura, devendo constar obrigatoriamente, o memorial descritivo da área requerida. Nesta esteira, em 1953, o DNPM formulou um manual técnico que apresentava a forma que este deveria ser realizado, o qual citamos:

É delimitada por um (indicação da figura que fôr, retângulo, quadrado etc.), tendo um vértice a tantos metros, no rumo tal, a partir do ponto qual (um ponto inconfundível do terreno) e cujos lados teem os seguintes cumprimentos e rumos magnéticos (ou verdadeiros indicação dos comprimentos e rumos, no sentido adotado 
para o caminhamento), conforme desenho de conjunto, em planta inclusa (Departamento Nacional de Produção Mineral, 1953, p.13) .

É importante destacar que a responsabilidade da escolha da jazida era do requerente, contudo, a responsabilidade técnica do memorial descritivo desta, ficava a cargo do engenheiro contrato para tal fim. Acerca desta situação, o manual técnico elaborado pelo DNPM em 1953, destacava que os aspectos técnicos oriundos da definição locacional da jazida não deveriam ser confiados a curiosos, visto que estes muitas das vezes ampliavam mapas municipais, inexatos a época (DNPM, 1953). A área a ser requerida deveria cumprir, dentre outras, as seguintes determinações:

A área será definida por uma poligonal tão simples quanto possível, representada em planta com comprimento e direção dos seus lados. O êrro de fechamento será o êrro comumente aceito em levantamentos topográficos. A figura será amarrada a um ponto inconfundível do terreno pela distância e rumo de um ou mais de seus vértices: marcos de estrada de ferro ou de rodagem regularmente quilometradas, cruzamentos de estradas, confluências de cursos d'água de denominação consagrada na região; e só excepcionalmente edifícios, de preferência industriais, quando muito conhecidos, com a indicação dos respectivos proprietários, bem como igrejas, obras d'arte, monumentos etc.; contando que uns e outros não distem mais de 1.000 metros do vértice considerado, elemento êsse que serão medidos diretamente no campo por processos expeditos de levantamento topográfico (a podômetro, bússola e aneroide), ou por método de levantamento de maior segurança (a cadeia e teodolito), a juízo do engenheiro a serviço do interessado na pesquisa, tendo em vista o tamanho da área e a precisão da definição, a existência, ou não, de áreas vizinhas já concedidas e as facilidades encontradas para proceder o levantamento do terreno (DNPM, 1953, p.18).

Cabe destacar que o ponto de coordenadas, a partir do qual iniciava-se a definição da área requerida, recebia o nome de ponto de amarração (PA). A representação deste, era realizada por intermédio de uma "planta autêntica, em escala, cujo tamanho fica a critério do engenheiro encarregado de executá-la" (DNPM, 1953, p.19). Esta deveria ser obrigatoriamente "apresentada em papel tela ou vegetal, desenhada em tinta nanquim exclusivamente, acompanhada de planta de situação, que poderá ser confeccionada na escala de 1:200.000 e na qual figurem córregos, estradas, etc., que deem idéia exata da localização da área pretendida" (DNPM, 1953, p.19). Acrescenta-se ainda, a obrigatoriedade da planta conter as seguintes indicações gráficas:

1ㅇ) a figura de delimitação da área a pesquisar, com a sua amarração a ponto inconfundível do terreno e trazendo a inscrição dos números e símbolos (comprimentos e rumos) que definem cada elemento de constituição da mesma figura;

2) a topografia da região do imóvel ou dos imóveis atingidos pelas pesquisas; 
3ㅇ) as vias de comunicação (estradas de ferro e de rodagem);

4ํ) os cursos d'água;

5) os edifícios e os limites aproximados das propriedades territoriais (com indicação dos nomes dos proprietários) que se encontram compreendidos no campo das pesquisas, sendo assim representados - a altimetria, por curvas de nível, de modo sucinto; a hidrografia- as estradas de ferro, edifícios, limites de propriedades e de concessões já outorgadas que porventura existam na região levantada em torno da área pretendida, - tudo em nanquim; as estradas de rodagem com os respectivos marcos quilometrados, se os houver (DNPM, 1953, p. 20).

Posteriormente, na égide do Período Militar, houve a promulgação do Código de Mineração (Decreto no 227 de 28/02/1967, que embora senil, ainda encontra-se em vigência no Brasil. Este, antes da modificação realizada na década de 1990, exigia nos termos do seu art. 16, que o requerimento inicial, fosse instruído, dentre outros documentos, com:

II - Designação das substâncias a pesquisar, a área em hectares, denominação e descrição da localização da área pretendida em relação aos principais acidentes topográficos da região, o nome dos proprietários das terras abrangidas pelo perímetro delimitador da área, Distrito, Município, Comarca e Estado.

III - Planta, em duas vias, figurando os principais elementos de reconhecimento, tais como, estradas de ferro, rodovias, pontes, túneis, marcos quilométricos, rios, córregos lagos, vilas, divisas das propriedades atingidas e confrontantes, bem assim a definição gráfica da área, em escala adequada, por figura geométrica, obrigatoriamente formada por segmentos de retas com orientação Norte-Sul e Leste-Oeste verdadeiros com 2 (dois) de seus vértices, ou, excepcionalmente, 1 (um), amarrado a ponto fixo e inconfundível do terreno e os lados definidos por comprimentos e rumos verdadeiros, além de planta de situação da área (BRASIL, 1967).

Na planta de detalhe, deveriam configurar os principais elementos de reconhecimentos tais, como: "rodovias, ferrovias, marcos quilométricos, túneis, edifícios, rios, divisas de propriedades, confrontações, etc." (DNPM, 1969, p.9). A definição da poligonal deveria ser formada obrigatoriamente por segmentos de retas orientadas nos rumos verdadeiros Norte-Sul e Leste Oeste, com seu ponto de amarração realizado em um ponto fixo e inconfundível do terreno, com um vetor de um único segmento de reta, cujo cumprimento não poderia exceder a 2.000 metros. A escolha deste, deveria ser realizado através de:

marcos quilométricos de estada de ferro ou rodagem, confluência de cursos dágua de denominação consagrada na região, marcos de triangulação, pontes, marcos de 
concessão de lavra como posse já imitida, edifícios de construção sólida, de preferência industriais, com o nome dos respectivos proprietários e ocupantes, etc. (DNPM, 1969, p.10).

A planta de situação deveria ter escala menor à planta de detalhe, oferecendo uma visão de conjunto, permitindo a relação das áreas com os principais acidentes geográficos da região, como: vias de acesso, rios, limites distritais e municipais, vilas e cidades, e trazer obrigatoriamente a assinatura do técnico habilitado com o registro no Conselho Regional de Engenharia e AgronomiaCREA (DNPM, 1969).

Tais procedimentos, só foram modificados pós redemocratização, quando em 1996, houveram algumas modificações no Código de Mineração de 1967, através da Lei no 9.314 de 14/11/1996, dentre estas, modificação nas documentações obrigatórias na apresentação do requerimento, nos termos da nova redação art. 16:

$V$-memorial descritivo da área pretendida, nos termos a serem definidos em portaria do Diretor-Geral do DNPM;

VI - planta de situação, cuja configuração e elementos de informação serão estabelecidos em portaria do Diretor-Geral do DNPM. (BRASIL, 1967).

Desta forma, e visando a regulamentação da modificação do Código de Mineração de 1967, o DNPM promulgou em 17/01/1997 a Portaria do Diretor Geral do DNPM no 15/1997, determinando que:

I - O memorial descritivo de que trata o inciso V, do artigo 16 do Código de Mineração, deverá ser apresentado em modelo de formulário aprovado pelo DNPM e conter a descrição da área pretendida delimitada por uma única poligonal, formada obrigatoriamente por segmentos de retas com orientação Norte-Sul e Leste-Oeste verdadeiros com um dos seus vértices amarrado a um ponto definido por coordenadas geográficas e os seus lados por comprimentos e rumos verdadeiros, e servirá como fonte exclusiva para a locação da área objeto do requerimento.

I.1 - As áreas deverão ser, preferencialmente, amarradas a pontos reconhecidos cartograficamente pelo DNPM, os quais estarão disponíveis nas Unidades Regionais, em suas áreas de competência, ou na Sede desta Autarquia.

II - A planta de situação de que trata o inciso VI, do artigo 16 do Código de Mineração deverá ser apresentada em escala adequada e conter, além da configuração gráfica da área, os principais elementos cartográficos. (DNPM, 1967).

Já na década passada, em 10/08/2008, o DNPM promulgou a Portaria DNPM n으 263/2008, modernizando a forma do requerimento às tecnologias disponíveis, tanto a nível da gestão da informação quanto às ciências geodésicas. Desta, destacamos os seguintes itens: 
Art. 2ㅇ 0 memorial descritivo da área deverá ser preenchido no modelo do formulário eletrônico disponibilizado no sítio do DNPM na internet e apresentado no protocolo do DNPM conforme legislação vigente, contendo a descrição da área pretendida formada por uma única poligonal, delimitada obrigatoriamente por vértices definidos por coordenadas geodésicas e datum South America (SAD-69)

$\S 1$ ․ Cada vértice, definido por coordenadas geodésicas, deverá formar com o vértice seguinte um segmento de reta Norte-Sul ou Leste-Oeste verdadeiros, vedado o cruzamento entre os segmentos de reta que formam os lados da poligonal. $\S 2$ O Os vértices deverão ser numerados seqüencialmente e o ponto de amarração (PA) será o primeiro vértice da poligonal da área objeto do requerimento.

Art. 40 O memorial descritivo servirá como fonte exclusiva para a locação da área no banco de dados do DNPM.

Art. 5o A planta de situação deverá ser georreferenciada, assinada por profissional legalmente habilitado e apresentada em escala adequada, contendo, além da configuração gráfica da área, os principais elementos cartográficos, tais como ferrovias, rodovias, dutovias e outras obras civis, rios, córregos, lagos, áreas urbanas, denominação das propriedades, ressaltando limites municipais e divisas estaduais, quando houver. (DNPM, 2008)

Finalmente, a partir da promulgação da Portaria DNPM no 76/2015, em 11/02/2015, o DNPM adotou como datum oficial, o Sistema de Referência Geocêntrico para as Américas -SIRGAS 2000 (DNPM, 2015).

\section{GESTÃO DAS INFORMAÇÕES PELO DNPM}

Aliado a toda a evolução da legislação, o DNPM principalmente ao longo das duas últimas décadas, avançou consideravelmente na gestão das informações em seus bancos de dados. Até meados do ano de 1970, para a obtenção de informações das áreas requeridas constantes no território nacional, e por conseguinte, requerer as áreas que estariam livres (não requeridas), o interessado comparecia obrigatoriamente aos Escritórios do DNPM para verificação da representação das poligonais já oneradas (requeridas) nas Cartas do IBGE. Posteriormente o DNPM passou a disponibilizar tais informações através de overlays, que pode ser definido como "a impressão de todas as poligonais de uma determinada região em um meio analógico" (PONTES, 2001, p.6). Por meio desta ferramenta, segundo o mesmo autor, o DNPM consolidava os polígonos dos processos minerários georreferenciados em um mapa, tornando-os disponíveis para que os interessados pudessem consultá-los, realizar verificações e análises espaciais, por intermédio de "mesas de luz".

Ainda nesta linha, foi introduzido a partir do ano 2000, a informatização das informações processuais por parte do DNPM, através do Sistema Cadastro Mineiro, responsável até os dias atuais por todo o gerenciamento dos processos minerários que tramitam no DNPM, atualmente na ordem de 183.321 ativos (DNPM, 2017). Segundo Silva (2006) o Cadastro Mineiro assegura aos 
interessados a transparência da tramitação dos processos, bem como permite a visualização das poligonais dos processos minerários ativos através do Sistema de Informação Geográficas da Mineração (SIGMINE). Acerca desta temática, o ex-diretor do DNPM, engenheiro de minas Miguel Nery, destacou que o advento do pré-requerimento eletrônico e as informações disponibilizadas pelo SIGMINE proporcionaram ao minerador "uma ferramenta segura, que informa aproximadamente em tempo real se a área está onerada" (SBGf, 2009). Na versão atual, disponibilizada aos interessados por intermédio do sítio do DNPM, as informações das poligonais requeridas encontram-se georreferenciadas e apresentadas por mapa digitais no formato vetorial e raster, no datum oficial do IBGE (SIRGAS 2000), tendo sua atualização diária, em face do dinamismo da base de dados.

\section{CONCLUSÃO}

É inegável que ao curso da história a legislação minerária vêm acompanhando as novas tecnologias, principalmente no que concerne as técnicas para demarcação e representação das poligonais requeridas pelos interessados visando o aproveitamento dos recursos minerais do país.

O Código de Minas de 1934, por exemplo, destacava que se possível, fosse apresentada pelo interessado uma "planta tosca" com a representação da área requerida e/ou manifestada, quando da existência anterior de jazidas/minas. A partir do Código de 1940, percebe-se a obrigatoriedade da apresentação por parte dos interessados de elementos técnicos visando a definição da área (memorial descritivo) e a representação desta em plantas. Já na vigência do cinquentenário Código de Mineração de 1967, foi possível a verificação da atualização da legislação visando uma maior segurança quanto à localização dos requerimentos e a representação destes em bancos de dados próprios. Um dos grandes avanços ocorridos nos últimos anos nesta temática, foi a transformação do ponto de amarração (PA) no primeiro vértice da poligonal requerida, eliminando assim, diversos problemas quanto à locação real da área, situação esta muito comum, levando a diversos processos de judicialização.

É inegável ainda, o avanço da transparência das informações relacionadas às áreas já requeridas, uma vez que estas em um passado remoto eram obtidas tão somente através de visitas aos escritórios do DNPM, para acesso a informação da representação das poligonais em Cartas ou através dos overlays. Atualmente, através de uma simples consulta ao sítio do DNPM, é possível através do SIGMINE, consultar todas as poligonais de processos ativos, realizar downloads dos arquivos vetoriais, facilitando a decisão de interessados quanto à realização de novos requerimentos em áreas ainda não requeridas (livres).

\section{REFERÊNCIAS}

BRASIL. Constituição Federal de 1988 (1988). Promulgada em 5 de outubro de 1988. Disponível em //www.planalto.gov.br/ccivil_03/Constituicao/Constituicao.htm 
BRASIL. Decreto no 24.642, de 10 de julho de 1934 (1934). Decreta o Código de Minas. Diário Oficial da União, Rio de Janeiro, RJ, Brasil.

BRASIL. Decreto no 1.985, de 29 de janeiro de 1940 (1940). Decreta o Código de Minas. Diário Oficial da União, Rio de Janeiro, RJ, Brasil.

BRASIL. Decreto Lei no 227, de 28 de fevereiro de 1967 (1967). Dá nova redação ao Decreto -Lei no1985, de 29 de janeiro de 1940. Diário Oficial da União, Brasília, DF, Brasil.

DEPARTAMENTO NACIONAL DE PRODUÇÃO MINERAL (1953). Como Requerer Pesquisa de Jazida Mineral- 4ㅇ Edição. Rio de Janeiro, RJ, Brasil.

DEPARTAMENTO NACIONAL DE PRODUÇÃO MINERAL (1969). Como obter autorização de pesquisa, concessão de lavra de jazida mineral e autorização para funcionar como emprêsa de mineração. Rio de Janeiro, RJ, Brasil.

DEPARTAMENTO NACIONAL DE PRODUÇÃO MINERAL (1997). Portaria no 15 de 13 de janeiro de 1997 publicada DOU de 15/01/1997, Diário Oficial da União, Brasília, DF, Brasil.

DEPARTAMENTO NACIONAL DE PRODUÇÃO MINERAL (2008). Portaria no 263 de 10 de julho de 2008 publicada no DOU de 11/07/2008, Diário Oficial da União, Brasília, DF, Brasil

DEPARTAMENTO NACIONAL DE PRODUÇÃO MINERAL (2015). Portaria no 76 de 10 de fevereiro de 2015 publicada no DOU de 11/02/2015, Diário Oficial da União, Brasília, DF, Brasil

DEPARTAMENTO NACIONAL DE PRODUÇÃO MINERAL, Banco de dados Cadastro Mineiro. Disponível em https://sistemas.dnpm.gov.br/SCM/Extra/site/ admin/pesquisarProcessos.aspx Acesso em 29/06/2017.

NOGUEIRA, L. R. (2004). Direito minerário brasileiro e as restrições à propriedade superficiária. (Dissertação de Mestrado). Universidade Estadual de Campinas-UNICAMP, Campinas/SP, Brasil.

PAIVA, A. A. (1967). A evolução do direito das minas e a constituição de 1967. Revista de Direito Administrativo, Rio de Janeiro, 90, 1-22.

SILVA, R. (2006). Processo de Outorga e Cadastro Mineiro. II Encontro Nacional de Produtores e Usuários de Informações Sociais, Econômicas e Territoriais. IBGE, Brasília, DF Brasil. Apresentação oral no IV CONFEGE. Disponível em http://www.anpad.org.br/diversos/apa/apa citacoes referencias.pdf.

TÁVORA, J. (1955). O Código de Minas e o Desenvolvimento da Mineração no Brasil. VII Semana de Estudos dos Problemas Mínero- Metalúrgicos do Brasil. Instituto de Engenharia de São Paulo, São Paulo, Brasil.

PORTES, R. G. (2001). Estudo das Técnicas para georreferenciar áreas de direitos minerários em sistemas de Informação Geográfica (Monografia). Universidade Federal de Minas Gerais UFMG, Belo Horizonte/MG, Brasil. 
SBGf- Sociedade Brasileira de Geofísica. (2009). Entrevista com diretor geral do DNPM. Recuperado em https://www.sbgf.org.br/home/index.php?option=com content\&view= article\&id=104:0-dnpm-e-o-setor-mineral-conquistas-eperspectivas\&catid=106\&ltemid=468. 